Tropical Journal of Pharmaceutical Research January 2020; 19 (1): 25-31

ISSN: $1596-5996$ (print); 1596-9827 (electronic)

(C) Pharmacotherapy Group, Faculty of Pharmacy, University of Benin, Benin City, 300001 Nigeria.

\title{
a-Mangostin protects against myocardial ischemia reperfusion injury by suppressing the activation of HIF-1a
}

\author{
Hong Jiang1, Wenli Guo², Dongdong Zhu', Wei Zhang1, Jing Yu', Manli Feng ${ }^{1}$, \\ Xiaoyu Wang ${ }^{2}$, Xiaopeng Wang ${ }^{2}$, Yanan Jiao ${ }^{3}$, Chengcheng Wang ${ }^{4}$, Yan Chen ${ }^{1 *}$ \\ ${ }^{1}$ Department of Cadre Health, ${ }^{2}$ Department of Emergency, ${ }^{3}$ Department of Acupuncture and Rehabilitation, Qingdao Hiser \\ Hospital; ${ }^{4}$ Department of Gynecology, Qilu Hospital of Shandong University (Qingdao Campus), Qingdao, Shandong 266000, \\ China
}

*For correspondence: Email: cgaws@yahoo.com; Tel: 0086-0532 83777278

Sent for review: 29 July 2019

Revised accepted: 20 December 2019

\begin{abstract}
Purpose: To investigate the cytoprotective effect of $\alpha$-mangostin on myocardial tissues in ischemic rats, and the underlying mechanism.

Methods: Histopathological changes in myocardial tissues were determined using inverted microscope. Protein expressions were measured by western blotting, while enzyme-linked immunosorbent assay (ELISA) was used to assay the expression levels of caspase-3, caspase-9 and caspase-8.

Results: Treatment with $\alpha$-mangostin $(20 \mathrm{mg} / \mathrm{kg}$ ) suppressed production of reactive oxygen species $(R O S)$ and lipid peroxides in myocardial tissues of MI/R rats, and significantly alleviated MI/R injurymediated reduction in ATP levels in cardiac tissues $(p<0.05)$. $\alpha$-Mangostin treatment of MI/R injury rats suppressed HIF-1a activation, and markedly elevated BNIP3 levels, relative to model group. Moreover, MI/R-induced cardiomyocyte apoptosis was significantly alleviated by $\alpha$-mangostin treatment $(p<0.05)$. Treatment with $\alpha$-mangostin also suppressed $/ / R$-induced increases in caspase-8 and caspase-3 activation in myocardial tissues, improved Nrf-2 activation, and promoted HO-1 and GST levels in MI/R injury rats $(p<0.05)$.

Conclusion: These results suggest that $\alpha$-mangostin protects rat cardiac tissues from MI/R-induced oxidative damage via reduction of HIF-1a expression, inhibition of ROS generation and suppression of apoptosis. Therefore, $\alpha$-mangostin may be of therapeutic importance for the management of myocardial ischemia in humans.
\end{abstract}

Keywords: $\alpha-M a n g o s t i n$, Hypoxia, Inflammation, Nrf-2, Oxidative stress, Reperfusion

This is an Open Access article that uses a fund-ing model which does not charge readers or their institutions for access and distributed under the terms of the Creative Commons Attribution License (http://creativecommons.org/licenses/by/4.0) and the Budapest Open Access Initiative (http://www.budapestopenaccessinitiative.org/read), which permit unrestricted use, distribution, and reproduction in any medium, provided the original work is properly credited.

Tropical Journal of Pharmaceutical Research is indexed by Science Citation Index (SciSearch), Scopus, International Pharmaceutical Abstract, Chemical Abstracts, Embase, Index Copernicus, EBSCO, African Index Medicus, JournalSeek, Journal Citation Reports/Science Edition, Directory of Open Access Journals (DOAJ), African Journal Online, Bioline International, Open-J-Gate and Pharmacy Abstracts

\section{INTRODUCTION}

Myocardial ischemia accounts for the highest mortality among various diseases of cardiovascular system worldwide [1]. Myocardial ischemia followed by reperfusion injury (MI/R injury) causes severe damage to cardiac tissues, leading to oxidative-nitrative stress and activation of inflammatory responses [2,3]. Excess accumulation of ROS, $\mathrm{Ca}^{2+}$ overload and ATP depletion initiate mitochondrial dysfunction. After reperfusion injury, cardiomyocytes are prone to 
increased mitochondrial stress which triggers apoptosis [2,4].

Hypoxia-inducing factor (HIF-1) plays a major role in MI/R injury [5]. Under normoxic conditions, HIF-1 is hydroxylated and acts as target for ubiquitinated proteasomal degradation. However, HIF-1 is stabilized and upregulated under low oxygen environments. Hypoxia inducing factor$1 \alpha$ regulates hypoxia-induced transcription of number of genes and regulates cardiac apoptosis [6]. Thus, hypoxia-induced gene alterations and redox imbalance act as important contributors in myocardial infarction. An effective approach to protecting the cardiomyocytes from $\mathrm{l} / \mathrm{R}$ injury could be achieved through pharmacological intervention. Some studies have shown the importance of antioxidants as protective agents against myocardial infraction [7-9]. Studies have revealed the significance of $\alpha$-mangostin as potent antioxidant with free radical scavenging property $[10,11]$. It has been reported that alpha-mangostin exerts protective effect against cisplatin-induced nephrotoxicity by reducing oxidative stress and inflammatory responses [12]. In addition, studies have demonstrated that $\alpha$-mangostin protects renal tubular cells against CDDP-induced apoptosis [13]. Alpha-mangostin mediates cardio-protection against $\beta$-adrenergic catecholamine-induced myocardial toxicity, and prevents oxidative stress and post-ischemic injury $[14,15]$.

The anti-cancer effects of $\alpha$-mangostin have been reported in a wide range of cancers including human leukemia cell line HL60 [16], human colon cancer $[17,18]$, prostate carcinoma [19] and head and neck squamous cell carcinoma [20]. The present study evaluated the antioxidant capacity of $\alpha$-mangostin and its cytoprotective effect against myocardial I/R injury in rats.

\section{EXPERIMENTAL}

\section{Establishment of myocardial ischemia/ reperfusion injury model}

Male Sprague-Dawley rats were housed in standard laboratory conditions (temperature and humidity of $25 \pm 2^{\circ} \mathrm{C}$ and $70 \%$, respectively, with alternating $12 \mathrm{~h}$ light/12 $\mathrm{h}$ and dark cycles) and ad libitum access to standard feed and clean drinking water. All animal experimental protocols were approved by the ethics committee of Qingdao Hiser Hospital, China. The study followed the guidelines of the Association for the Assessment and Accreditation of Laboratory Animal Care International (AAALAC) for experimentation and animal use.
Rats weighing 200 - $250 \mathrm{~g}$ were randomly divided into 4 groups: sham, a-mangostin, myocardial $\mathrm{I} / \mathrm{R}$ injury, and a-mangostin + myocardial $I / R$ injury groups. After the period of acclimatization, the rats were anesthetized with sodium pentobarbital intraperitoneally (i.p.) at a dose of $40 \mathrm{mg} / \mathrm{kg}$ body weight. Myocardial I/R injury was established via left thoracic incision, followed by slipknot around left anterior descending coronary artery (LAD). The slipknot was removed after $30 \mathrm{~min}$, after which a 2-h reperfusion was carried out. Similar surgical procedures were done for control animals, but without LAD occlusion. Alpha-mangostin ( $\geq 98$ $\%$, Sigma Aldrich) was dissolved in mixture of DMSO and ethanol, and administered intravenously to the rats at a dose of $20 \mathrm{mg} / \mathrm{kg}$ $15 \mathrm{~min}$ before reperfusion. Based on preliminary studies using different doses $(5,10,20$ and 30 $\mathrm{mg} / \mathrm{kg}$ ), the dose of $20 \mathrm{mg} / \mathrm{kg}$ was selected. Doses above $20 \mathrm{mg} / \mathrm{kg}$ showed similar cytoprotective effects. Thus, the lower dose with significant cytoprotection was chosen for further detailed studies.

\section{Histopathological studies}

Heart tissues were fixed in $4 \%$ paraformaldehyde and embedded in paraffin. The tissues were cut into thin sections $(2-\mu \mathrm{m})$ and subsequently de-paraffinized in boiling xylene prior to hematoxylin and eosin (H\&E) staining. The stained tissues were analyzed for histopathological changes with the aid of light microscopy.

\section{Determination of ROS levels}

Hearts were excised from the rats, washed with PBS, and then embedded in O.C.T (SAKURA). The tissues were cut into thin sections 2- $\mu \mathrm{m}$ thick, and subsequently subjected to determination of ROS levels.

\section{Measurement of lipid peroxidation}

Homogenized cardiac tissues were analyzed for lipid peroxide content using commercially available Lipid Peroxidation Assay Kit (Sigma Aldrich, St. Louis, MO) according to instructions from the manufacturer. The lipid peroxide levels were expressed as TBARS ( $\mathrm{ng} / \mathrm{mg}$ protein).

\section{Determination of adenosine triphosphate (ATP) contents}

Levels of ATP in the homogenized cardiac tissue samples were measured using Cayman's ATP Detection Assay Kit, as per manufacturer's instructions. 


\section{Evaluation of antioxidant enzyme activities}

The activities of antioxidant enzymes and GSH levels in homogenized heart tissues were assayed using Sigma Aldrich assay kits for SOD (19160), GST (CS0410) and GPx (CGP1) and GSH (CS0260). The assays were performed as per the technical instructions given by the manufacturer (Sigma Aldrich, St. Louis, MO). The results are expressed as Units/mg of protein.

\section{Assay of caspase 8, 9 and 3 activities}

Heart homogenates were analyzed for caspase expressions using ELISA assay kits for caspase 8 (ab119507, Abcam), caspase 9 (ab119508, Abcam) and caspase 3 (Human Active Caspase3 ELISA Kit, Thermo Scientific), as per manufacturer's instructions.

\section{Western blot studies}

The cardiac tissues were minced, washed with cold D-PBS and subsequently suspended in $1 \%$ collagenase. Following 50-min collagenase treatment at $37^{\circ} \mathrm{C}$, the tissues were suspended in $0.25 \%$ trypsin for $10 \mathrm{~min}$. The lysate was centrifuged for $30 \mathrm{~min}$ at $4{ }^{\circ} \mathrm{C}$ at $12000 \mathrm{~g}$, and the protein content of the supernatant was measured using bicinchoninic acid (BCA) assay. Then, protein samples $(60 \mu \mathrm{g})$ were subjected to $12 \%$ SDS-polyacrylamide gel electrophoresis. The separated proteins were transferred to PVDF membrane and blocked in $5 \%$ skimmed milk for $1 \mathrm{~h}$. The membrane was washed 5 times with TBST, and then incubated with primary antibodies overnight at $4^{\circ} \mathrm{C}$. The antibodies used were: anti-NF-kb-p65 (ab16502), anti-Nrf-2 (sc722), anti-HO-1 (sc-10789), anti-GST (ab9085), anti-COX-2 (ab15191), anti-Bnip3 (ab10433) and anti-HIF-1 $\alpha$. After incubation, the membrane was washed with TBST, and then incubated with peroxidase-conjugated goat anti-mouse or rabbit IgG secondary antibody for $2 \mathrm{~h}$ at room temperature. The membrane was visualized with enhanced chemiluminescent system, and images were scanned for densitometric analysis using Image J software (Supersignal; Pierce, IL).

\section{Statistical analysis}

All the experiments were performed in triplicate. The data were analyzed using one-way analysis of variance (ANOVA) and Student's t-test. Differences were considered statistically significant at $p<0.05$ )

\section{RESULTS}

\section{a-Mangostin protected cardiac tissues against myocardial $\mathbf{~ / R}$}

Myocardial $\mathrm{I} / \mathrm{R}$ injury significantly induced degeneration of cardiac tissues in rats, when compared to sham control (Figure $1 \mathrm{~A}$ ). However, histopathological changes were absent in the cardiac tissues of control and a-mangostin treatment groups. The production of reactive oxygen species and lipid peroxides were markedly enhanced in rat cardiac tissues after myocardial I/R (Figure $1 \mathrm{~B}$ ). However, treatment of myocardial $\mathrm{I} / \mathrm{R}$ rats with a-mangostin significantly inhibited production of ROS and lipid peroxides.

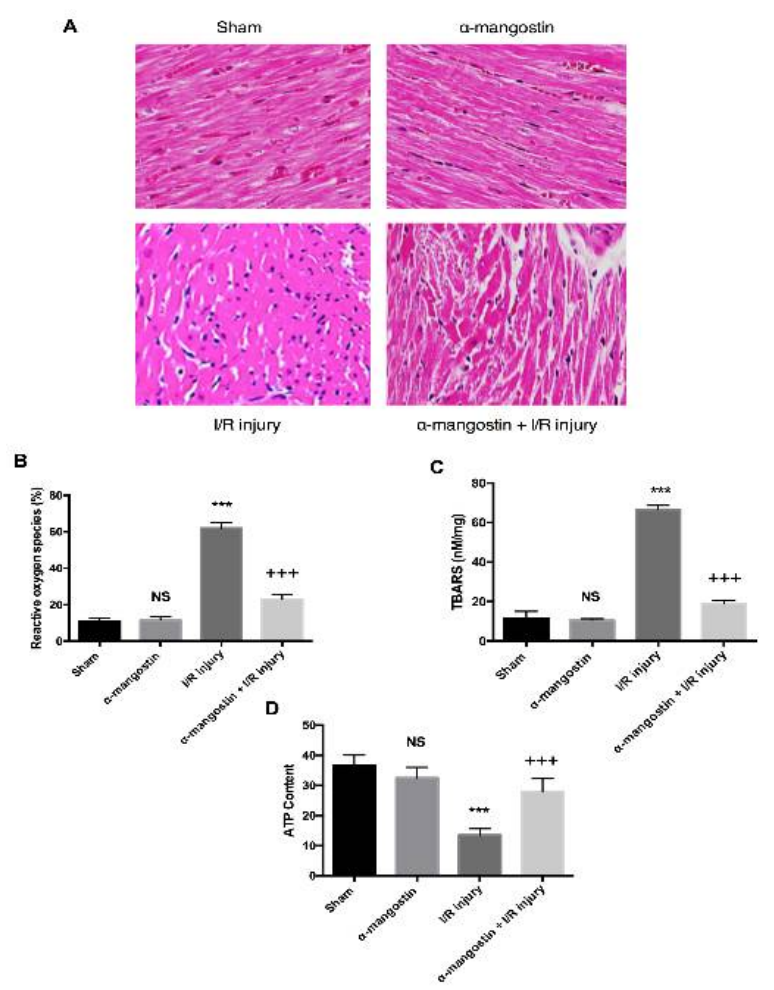

Figure 1: Effect of a-mangostin on oxidative stress and myocardial damage in $\mathrm{I} / \mathrm{R}$ injury rats. (A) Histopathological changes in $\mathrm{I} / \mathrm{R}$ injury rats. (B) Production of ROS. (C) Lipid peroxide levels. (D) Relative ATP levels. ${ }^{* * *} p<0.001$, when compared to sham group; $+++p<0.001$ when compared to I/R injury group

a-Mangostin suppressed myocardial $\quad / / R$ injury -induced activation of HIF-1a and inflammation

Myocardial $\mathrm{L} / \mathrm{R}$ injury significantly increased hypoxia inducible factor-1 $\alpha$ expression, when compared to control rats. The expression of Bnip3, a pro-apoptotic protein involved in regulation of apoptosis, was significantly 
increased in $\mathrm{I} / \mathrm{R}$ injury rats, relative to sham group. Moreover, I/R injury induced inflammatory activation by up-regulating NF-kB and COX-2 expressions, when compared to sham rats. However, pre-treatment with a-mangostin prevented HIF-1a activation and subsequent downregulation of inflammatory markers, when compared to myocardial I/R injury rats (Figures 2 A - D)

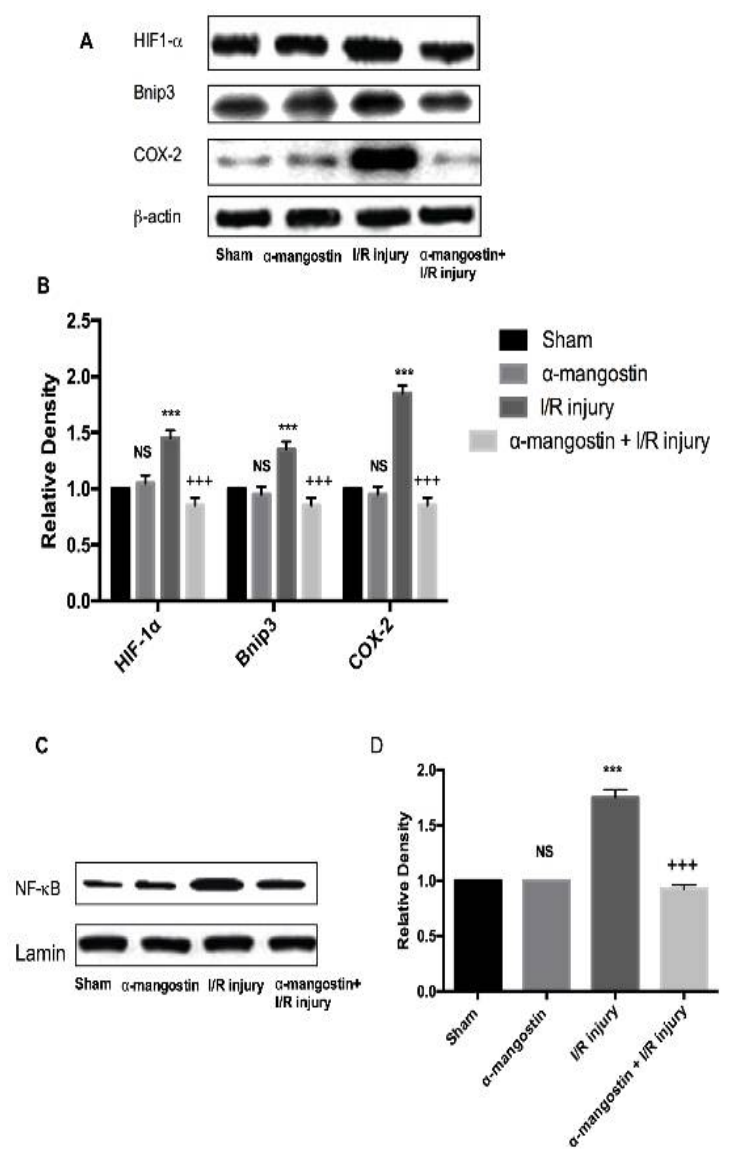

Figure 2: Effect of $\alpha$-mangostin on HIF-1 $\alpha$ and inflammation activation. (A) HIF-1a, Bnip3 and COX-2 expressions in rats treated with $\alpha$-mangostin. (B) Relative protein expressions normalized to $\beta$-actin. (C) Suppression of NF-kb expression. (D) Relative NF-kb expression; ${ }^{* * *} p<0.001$, when compared to sham rats; ${ }^{+++} p<0.001$, when compared to I/R injury group

\section{a-Mangostin prevented myocardial $\mathbf{I} / \mathbf{R}$ injury- mediated suppression of Nrf-2 target gene expressions}

Nrf-2 and its downstream genes are important regulators of redox balance. In the present study, myocardial I/R injury significantly down-regulated expressions of Nrf-2, HO-1, GST and antioxidant enzyme activities, when compared to sham group. However, pre-treatment with a-mangostin significantly improved the overall redox balance by up-regulating Nrf-2 target genes and antioxidant levels. These results are depicted in Figures 3 A - E).

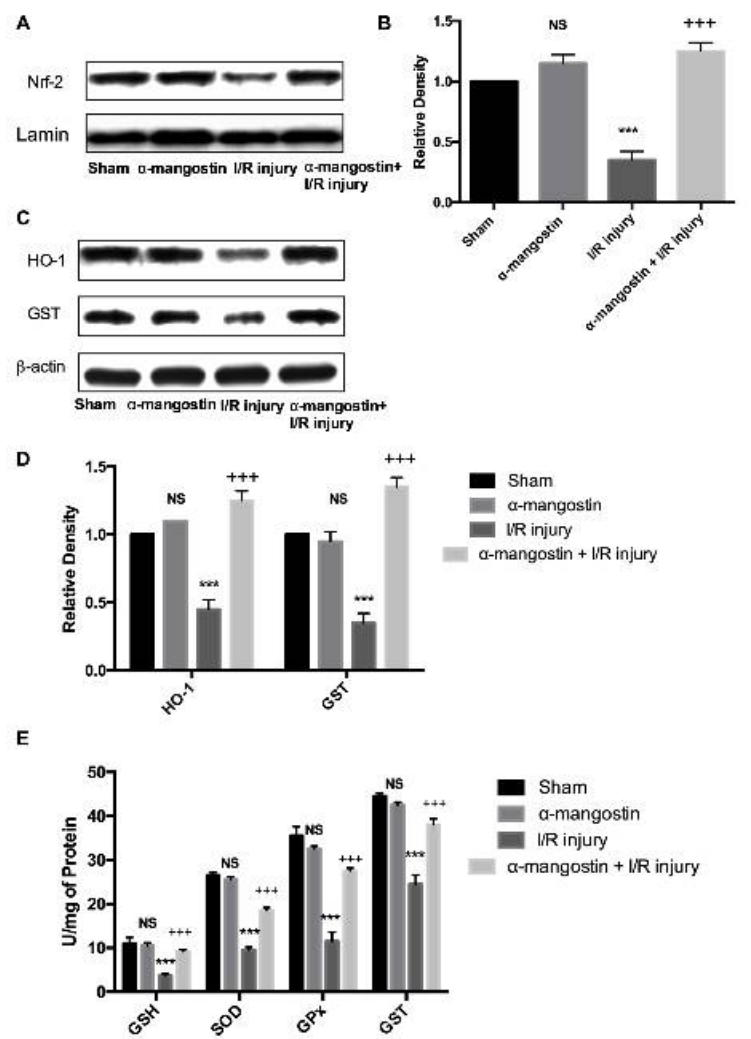

Figure 3: Effect of $\alpha$-mangostin on Nrf-2 expression and antioxidant pool. (A) The a-mangostin increased Nrf-2 expressions. (B) Relative Nrf-2 expression compared to Lamin. (C) a-mangostin up regulated GST and HO-1 expressions. (D) Densitometry of GST and HO-1 expressions. (E) a-mangostin improved antioxidant pool in I/R injury mice; ${ }^{* *} p<0.001$, when compared to sham rats; $+++p<0.001$, when compared to I/R injury group

\section{Myocardial I/R injury induced apoptosis was prevented by a-mangostin}

Myocardial I/R injury significantly increased the expressions of caspase- 8 and caspase-3, relative to sham group, suggesting activation of the intrinsic apoptotic pathway. However, pretreatment with a-mangostin suppressed apoptosis, maintained membrane potential, and down-regulated caspase expressions (Figures 4 $A$ and $B$ ).

\section{DISCUSSION}

The present study demonstrates that $\alpha$ mangostin pre-treatment prevents degeneration of myocardial tissues in myocardial $1 / R$ injury in rats via inhibition of oxidative stress. The myocardial I/R injury-induced HIF-1a and 


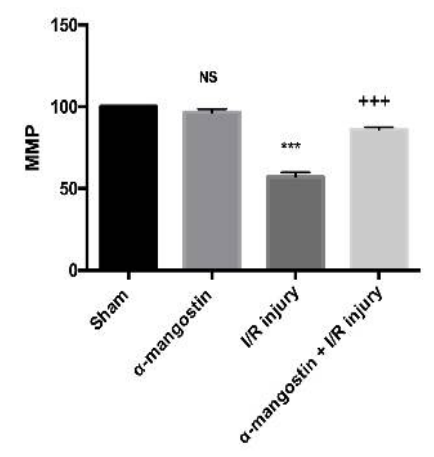

B

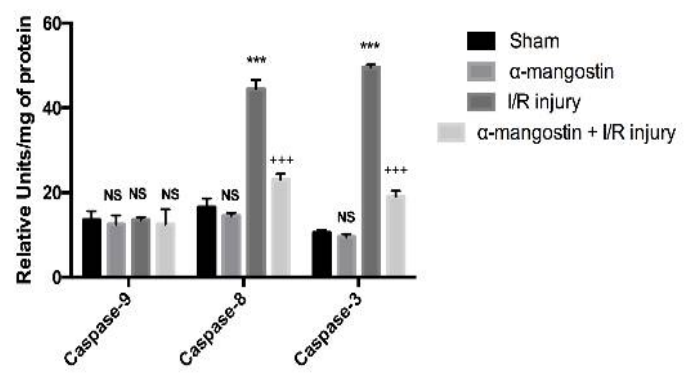

Figure 4: Effect of $\alpha$-mangostin on apoptosis in $1 / R$ injury mice. (A) Effect of $\alpha$-mangostin and I/R injury on MMP levels. (B) Down-regulation of caspase expressions in $\mathrm{I} / \mathrm{R}$ injury rats by $\alpha$-mangostin; $p<0.001$, when compared to sham mice; ${ }^{+++} p<0.001$, when compared to I/R injury group

inflammation activation were suppressed by $\alpha$ mangostin treatment. a-Mangostin also prevented myocardial $\mathrm{I} / \mathrm{R}$ injury-induced apoptosis. Myocardial ischemic injury/reperfusion leads to exacerbated myocardial damage. Oxidative stress is one of the important contributors to such events. Thus, antioxidant treatment can offer protection against myocardial injury [21].

In the present study, oxidative stress was significantly increased under $\mathrm{l} / \mathrm{R}$ injury, with increased levels of ROS and lipid peroxides, and decline in ATP content. These results are in line with previous reports implicating oxidative stress as a major regulator of myocardial $\mathrm{l} / \mathrm{R}$ injury $[22,23]$. Treatment with $\alpha$-mangostin significantly reduced the oxidative stress, increased myocardial ATP levels, and decreased cell degeneration in myocardial tissue. It has been reported that $\alpha$-mangostin exhibits cytoprotective effect through reduction of oxidation of lowdensity lipoproteins, as well as free radical scavenging and inhibition of apoptosis $[24,25]$.

Hypoxia-inducing factor-1a regulates cellular oxygen homeostasis and imparts adaptation to cellular survival or death. Hypoxia-inducing factor-1a is degraded under normoxia through prolyl hydroxylase-mediated ubiquitinproteasome pathway. During hypoxia, stabilization of HIF-1a via inhibition of prolyl hydroxylases is followed by its heterodimerization with HIF-1 $\beta$, and subsequent translocation to the nucleus where it regulates transcription of target genes [26]. Hypoxiainducing factor- $1 \alpha$ mediates apoptosis through activation of pro-apoptotic proteins [27].

Direct regulatory role of HIF-1a on the expression of mitochondrial pro-apoptotic protein BNIP3 (Bcl-2/E1B $19 \mathrm{kDa}$ interacting protein 3) is involved in apoptotic induction [28]. Thus, the significant up-regulation in HIF-1 $\alpha$ after myocardial $\mathrm{I} / \mathrm{R}$ injury is consistent with previous reports [4]. Moreover, there were increases in the expressions of inflammatory markers such as NF-KB and COX-2 following $\mathrm{I} / \mathrm{R}$ injury. These observations show evidence that myocardial I/R injury evokes hypoxia-induced inflammatory responses. Previous studies reported the involvement of hypoxia and HIF-1a in inflammatory activation and apoptosis during $\mathrm{I} / \mathrm{R}$ injury $[29,30]$.

In the present study, myocardial $\mathrm{l} / \mathrm{R}$ injury resulted in apoptotic induction through significant up-regulation of the expressions of BNIP3, caspase 9 and caspase-3. Pre-treatment with $\alpha-$ mangostin resulted in anti-inflammatory and antiapoptotic effects against myocardial $\mathrm{l} / \mathrm{R}$ injury. The inhibitory effect of $\alpha$-mangostin against secretion of the pro-inflammatory mediators IL-8 and TNF-a has been previously demonstrated [31]. The anti-cancer effect of $\alpha$-mangostin in HT29 cells is mediated through upregulation of Wnt and Bcl-2 expressions [32]. It has been reported that $\alpha$-mangostin suppresses MMP expressions and prevents prostate cancer metastasis through the JNK pathway [33].

Cellular protection against oxidative stress and cell death is attributed to redox homeostasis. In the present study, myocardial I/R injury significantly suppressed antioxidant production in rat myocardial tissues. Nuclear factor erythroid (Nrf-2) is a key transcription factor which binds to antioxidant response elements (ARE) and induces target antioxidant gene expressions [34]. Activated Nrf-2 is highly stable and its aggregation in the nucleus leads to cytoprotection [35].

The present study demonstrated that $\alpha$ mangostin significantly improves cardiac function in MI/R injury rats by up-regulation of Nrf-2 and its downstream targets HO-1 and GST. These findings are consistent with reports published earlier on a-mangostin-mediated protective effect 
against age-related macular degeneration through Nrf-2 and MAPK-mediated signaling $[25,36]$.

\section{CONCLUSION}

These results suggest that $\alpha$-mangostin exhibits protective effect against myocardial ischemic injury in rats via the regulation of HIF-1 $\alpha$ and Nrf2 signaling. Therefore, a-mangostin can potentially be used for the treatment of myocardial ischemic injury.

\section{DECLARATIONS}

\section{Conflict of interest}

No conflict of interest is associated with this work.

\section{Contribution of authors}

We declare that this work was done by the author(s) named in this article and all liabilities pertaining to claims relating to the content of this article will be borne by the authors. Hong Jiang, Yan Chen- conceived and designed the study; Wei Zhang, Jing Yu, Manli Feng, Xiaoyu Wang, Xiaopeng Wang, Yanan Jiao, Chengcheng Wang- collected and analyzed the data; Hong Jiang, Wen li Guo, Dongdong Zhu -wrote the manuscript. Yan Chen-Approved final version of the manuscript. All authors read and approved the manuscript for publication.

\section{Open Access}

This is an Open Access article that uses a funding model which does not charge readers or their institutions for access and distributed under the terms of the Creative Commons Attribution License (http://creativecommons.org/licenses/by/ 4.0) and the Budapest Open Access Initiative (http://www.budapestopenaccessinitiative.org/rea d), which permit unrestricted use, distribution, and reproduction in any medium, provided the original work is properly credited.

\section{REFERENCES}

1. Domanski MJ, Fuster V, Diaz-Mitoma F, Grundy S, LloydJones $D$, Mamdani $M$, Roberts $R$, Thorpe $K$, Hall J, Udell JA, et al. Next Steps in Primary Prevention of Coronary Heart Disease: Rationale for and Design of the ECAD Trial. J Am Coll Cardio 2015; 66: 1828-1836.

2. Meng $L M$, Ma $H J$, Guo $H$, Kong $Q Q$, Zhang $Y$. The cardioprotective effect of naringenin against ischemiareperfusion injury through activation of ATP-sensitive potassium channel in rat. Can J Physiol Pharmacol 2016; 94: 973-978.

3. Kurian GA, Rajagopal $R$, Vedantham $S$, Rajesh $M$. The Role of Oxidative Stress in Myocardial Ischemia and Reperfusion Injury and Remodeling: Revisited. Oxid Med Cell Longev 2016; 1656450.

4. Loor G, Kondapalli J, Iwase H, Chandel NS, Waypa GB, Guzy RD, Vanden TL Hoek, Schumacker PT. Mitochondrial oxidant stress triggers cell death in simulated ischemia-reperfusion. Biochim Biophys Acta 2011; 1813: 1382-1394.

5. Zhao $H X$, Wang $X L$, Wang $Y H$, Wu $Y, L i X Y, L v X P$, Zhao $Z Q$, Zhao RR, Liu HR. Attenuation of myocardial injury by postconditioning: role of hypoxia inducible factor1alpha. Basic Res Cardiol 2010; 105: 109-118.

6. Bruick RK. Expression of the gene encoding the proapoptotic Nip3 protein is induced by hypoxia Proc Natl Acad SciU S A 2000; 97:9082-9087.

7. Li $H$, Xie $Y H$, Yang $Q$, Wang SW, Zhang BL, Wang JB, Cao W, Bi LL, Sun JY, Miao S, et al. Cardioprotective effect of paeonol and danshensu combination on isoproterenol-induced myocardial injury in rats. PLoS One 2012; 7: e48872.

8. Zhou M, Ren H, Han J, Wang W, Zheng Q, Wang D. Protective Effects of Kaempferol against Myocardial Ischemia/Reperfusion Injury in Isolated Rat Heart via Antioxidant Activity and Inhibition of Glycogen Synthase Kinase-3. Oxidative Medicine and Cellular Longevity 2015; Article ID 481405, 8.

9. Whitman GJ, Niibori K, Yokoyama H, Crestanello JA, Lingle DM, Momeni R. The mechanisms of coenzyme Q10 as therapy for myocardial ischemia reperfusion injury. Mol Aspects Med 1997; 18: S195-203.

10. Martínez A, Galano A, Vargas $R$. Free radical scavenger properties of $\alpha$-mangostin: thermodynamics and kinetics of HAT and RAF mechanisms, J Phys Chem B 2011; 115: 12591-12598.

11. Ngawhirunpat $T$, Opanasopi $P$, Sukma $M$, Sittisombut $C$, Kat A, Adachi I. Antioxidant, free radical-scavenging activity and cytotoxicity of different solvent extracts and their phenolic constituents from the fruit hull of mangosteen (Garcinia mangostana). Pharm Biol 2010; 48: 55-62.

12. Pérez-Rojas JM, Cruz C, García-López $P$, SánchezGonzález DJ, Martínez-Martínez CM, Ceballos G, M Espinosa, Meléndez-Zajgla J, Pedraza-Chaverri J. Renoprotection by alpha-Mangostin is related to the attenuation in renal oxidative/nitrosative stress induced by cisplatin nephrotoxicity. Free Radic Res 2009; 43 : 1122-1132.

13. Sánchez-Pérez Y, Morales-Bárcenas R, García-Cuellar CM, López-Marure $R$, Calderon-Oliver M, PedrazaChaverri J, Chirino YI. The alpha-mangostin prevention on cisplatin-induced apoptotic death in LLC-PK1 cells is associated to an inhibition of ROS production and p53 induction. Chem Biol Interact 2010; 188: 144-150.

14. Devi Sampath P, Vijayaraghavan K. Cardioprotective effect of alpha-mangostin, a xanthone derivative from

Trop J Pharm Res, January 2020; 19(1): 30 
mangosteen on tissue defense system against isoproterenol-induced myocardial infarction in rats. $J$ Biochem Mol Toxicol 2007; 21: 336-339.

15. Buelna-Chontal M, Correa F, Hernández-Reséndiz S, Zazueta C, Pedraza-Chaverri J. Protective effect of $\alpha$ mangostin on cardiac reperfusion damage by attenuation of oxidative stress. J Med Food 2011; 14: 1370-1374.

16. Matsumoto K, Akao Y, Yi H, Ohguchi K, Ito T, Tanaka T, Kobayashi E, linuma M, Nozawa Y. Preferential target is mitochondria in alpha-mangostin-induced apoptosis in human leukemia HL60 cells. Bioorg Med Chem 2004; 12: 5799-5806.

17. Nabandith $V$, Suzui M, Morioka $T$, Kaneshiro $T$, Kinjo $T$, Matsumoto K, Akao Y, linuma M, Yoshimi N. Inhibitory effects of crude alpha-mangostin, a xanthone derivative, on two different categories of colon preneoplastic lesions induced by 1, 2-dimethylhydrazine in the rat. Asian Pac J Cancer Prev 2004; 5: 433-438.

18. Matsumoto $K$, Akao $Y$, Ohguchi $K$, Ito $T$, Tanaka $T$, linuma $M$, Nozawa $Y$. Xanthones induce cell-cycle arrest and apoptosis in human colon cancer DLD-1 cells. Bioorg Med Chem 2005; 13: 6064-6069.

19. Hung SH, Shen KH, Wu CH, Liu CL, Shih YW. Alphamangostin suppresses $P C$-3 human prostate carcinoma cell metastasis by inhibiting matrix metalloproteinase-2/9 and urokinase-plasminogen expression through the JNK signaling pathway. J Agric Food Chem 2009; 57: 1291 1298.

20. Kaomongkolgit R, Chaisomboon N, Pavasant $P$. Apoptotic effect of alpha-mangostin on head and neck squamous carcinoma cells. Arch Oral Biol 2010; 56 : 483-490.

21. Moens AL, Claeys MJ, Timmermans JP, Vrints CJ. Myocardial ischemia/reperfusion-injury, a clinical view on a complex pathophysiological process. Int J Cardiol 2005; 100: 179-190.

22. Turer AT, Hill JA. Pathogenesis of myocardial ischemiareperfusion injury and rationale for therapy. $A m \mathrm{~J}$ Cardiol 2010; 106: 360-368.

23. Hu L, Wang J, Zhu H, Wu X, Zhou L, Song Y, Zhu S, Hao $M$, Liu $C$, Fan $Y$, et al. Ischemic postconditioning protects the heart against ischemia-reperfusion injury via neuronal nitric oxide synthase in the sarcoplasmic reticulum and mitochondria. Cell Death Dis 2016; 12; 7:e2222.

24. Márquez-Valadez B, Lugo-Huitrón $R$, Valdivia-Cerda $V$, Miranda-Ramírez LR, Pérez-De La Cruz V, GonzálezCuahutencos O, Rivero-Cruz I, Mata R, Santamaría A, Pedraza-Chaverrí J. The natural xanthone alphamangostin reduces oxidative damage in rat brain tissue. Nutr Neurosci 2009; 12: 35-42.
25. Fang $Y$, Su T, Qiu $X$, Mao $P, X u Y$, Hu Z, Zhang $Y$, Zheng $X$, Xie $P$, Liu $Q$. Protective effect of alphamangostin against oxidative stress induced-retinal cell death. Sci Rep 2016; 6: 21018.

26. Greijer $A E$, van der Wall E. The role of hypoxia inducible factor 1 (HIF-1) in hypoxia induced apoptosis. J Clin Pathol 2004; 57: 1009-1014.

27. Chen N, Chen X, Huang R, Zeng H, Gong J, Meng W, Lu $Y$, Zhao F, Wang L, Zhou Q. BCL-xL is a target gene regulated by hypoxia-inducible factor-1a. J Biol Chem 2009; 284: 10004-10012.

28. Althaus J, Bernaudin M, Petit E, Toutain J, Touzani O, Rami A. Expression of the gene encoding the proapoptotic BNIP3 protein and stimulation of hypoxiainducible factor-1alpha (HIF-1alpha) protein following focal cerebral ischemia in rats. Neurochem Int 2006; 48 : 687-695.

29. Palazon A, Goldrath AW, Nizet V, Johnson RS. HIF transcription factors, inflammation, and immunity. Immunity 2014; 41: 518-528.

30. Imtiyaz HZ, Simon MC. Hypoxia-inducible factors as essential regulators of inflammation. Curr Top Microbiol Immunol 2010; 345: 105-120.

31. Gutierrez-Orozco F, Chitchumroonchokchai C, Lesinski GB, Suksamrarn S, Failla ML. a-Mangostin: antiinflammatory activity and metabolism by human cells. J Agric Food Chem 2013; 61: 3891-900.

32. Chitchumroonchokchai C, Thomas-Ahner JM, Li J, Riedl KM, Nontakham J, Suksumrarn S, Failla ML. Antitumorigenicity of dietary $\alpha$-mangostin in an HT-29 colon cell xenograft model and the tissue distribution of xanthones and their phase II metabolites. Mol Nutr Food Res 2013; 57: 203-211.

33. Hung $\mathrm{SH}$, Shen $\mathrm{KH}, \mathrm{Wu} \mathrm{CH}$, Liu CL, Shih YW. Alphamangostin suppresses $P C$-3 human prostate carcinoma cell metastasis by inhibiting matrix metalloproteinase-2/9 and urokinase-plasminogen expression through the JNK signaling pathway. J Agric Food Chem 2009; 57: 1291 1298.

34. Ma Q. Role of nrf2 in oxidative stress and toxicity. Annu Rev Pharmacol Toxicol 2013; 53: 401-426.

35. Nguyen $T$, Nioi $P$, Pickett CB. The Nrf2-antioxidant response element signaling pathway and its activation by oxidative stress. J Biol Chem 2009; 284: 13291 1325.

36. Shen $Q$, Chitchumroonchokchai C, Thomas JL, Gushchina LV, Disilvestro D, Failla ML, Ziouzenkova $O$. Adipocyte reporter assays: application for identification of anti-inflammatory and antioxidant properties of mangosteen xanthones. Mol Nutr Food Res 2014; 58 : 239-247. 